\title{
Constructivist Learning: Understanding and Experience in IT Tertiary Education
}

\author{
Shang Gao ${ }^{1, *}$, Jo Coldwell-Neilson ${ }^{1}$ \& Andrzej Goscinski ${ }^{1}$ \\ ${ }^{1}$ School of Information Technology, Deakin University, Victoria, Australia \\ *Corresponding author: School of Information Technology, Deakin University, Victoria, Australia. \\ Tel: 61-3-522-71383. E-mail: shang@deakin.edu.au
}

Received: August 30, 2013

doi:10.5430/jct.v2n2p140
Accepted: October 30, 2013 Online Published: November 14, 2013

URL: http://dx.doi.org/10.5430/jct.v2n2p140

\begin{abstract}
This paper firstly introduces the concept of constructivist learning which advocates that students actively construct knowledge themselves with teachers' assistance. Based on the six important elements of constructivist learning and teaching planning approach, detailed examples of designing the six constructivist elements of situation, groupings, bridge, questions, exhibit, and reflections for two units offered at school of Information Technology, Deakin University are provided. A conclusion emphasizing the learners' difference to be paid attention to while educators designing curriculum on CloudDeakin platform is made at the end of this paper.
\end{abstract}

Keywords: constructivist learning; teaching and learning; tertiary education; higher education in IT; CloudDeakin; reflection; ePortfolio

\section{Introduction}

As a teacher, we used to plan our lectures in a conventional way by focusing on what we should do to direct students, but not what the students should do. This teaching approach is what we are familiar with as it is the way we were educated. It is also found this conventional mode often resulted in passive listening rather than active thinking and interaction in our own experience. Are there any approaches to helping solve this passive learning problem? The constructivist learning theory is one of these solutions introduced by George W. Gagnon (George, 2001). It emphasizes the importance of learners active participance in the learning process. In this process, teachers are expected to "organize what learners will do rather than plan their teaching behaviors". How this approach would help students actively construct knowledge themselves and become independent learners in our teaching practice?

In the following sections, we first introduce the constructivist learning theory, then describe our understanding of how constructivist learning and teaching helps in our teaching, followed by the review of a range of learning activities based on our teaching experience in IT tertiary education. A conclusion emphasizing the learners' difference to be paid attention to while teachers designing curriculum are made at the end of this paper.

\section{Background}

Usually when we teachers explain concepts to students, verbal descriptions or visual demonstrations are adopted. This phenomenon is quite common and consistent with the classroom activities described in John Goodlad's research report conducted thirty years ago (Goodlad, 1984). In his report, Goodlad found that most of the time, most of the teachers were talking to the students. But asking them whether they enjoyed their classes, students answered that they were most interested in physical education, fine arts, or industrial arts because they could experiment on something. In those hands-on classes they are active learners instead of being passive recipients of information. This is a typical case of constructivism: students are constructing knowledge based on what they experience and understand in the process. Engaging them in active learning is the key of constructivist learning theory. 


\subsection{What is Constructivist?}

After searching the Internet for the definition of constructivist learning, we got many explanations from different sources. We are thinking that if educators were asked to answer this question, "What is constructivism?" The results could be also different, reflecting different understanding of the term and the text. This is a good example that what we read does not produce a single meaning but different understanding is constructed by us based on our prior knowledge and experience.

The following explanation of constructivist learning reflects the understanding of constructivism. Stacey, E. provided a summary of constructivists and social constructivist theories in her Ph.D. thesis.

"Many of the constructivist ideas of learning originated from the work of cognitive psychologists such as Piaget, Bruner and Vygotsky who shared a central notion of constructivism in which the learner had a representational model, a system of schema or personal constructs which provided an anticipatory scheme for the learner to make sense of any situation (Stacey, 1998). Thus constructivism in learning is concerned with: How learners construe (or interpret) events and ideas, and how they construct (build or assemble) structures of meaning. The constant dialectical interplay between construing and constructing is at the heart of a constructivist approach to education (Stacey, 1998) (Candy, 1991).”

Constructivist theory assumes that learners construct their own knowledge on the basis of interaction with their environment. Four assumptions are made for "constructivist learning” (George, 2001): knowledge is physically constructed when learners are involved in active learning; knowledge is symbolically and socially constructed when learners behave and present their meaning; knowledge is theoretically constructed when learners try to explain things they don't completely understand.

With these common assumptions, our conventional teaching planning according to the Tyler models (Tyler, 2013) is no longer adequate. So how can teachers like us plan for constructivist learning and constructivist teaching?

\subsection{Six Elements of Constructivist Learning}

George W. Gagnon etc. proposed an approach for planning using a "Constructivist Learning Design" that honors the common assumptions of constructivism and thinks about the constructive activities of the learner rather than the demonstrative behavior of the teacher.

This approach emphasizes six important elements: Situation, Groupings, Bridge, Questions, Exhibit, and Reflections. The relationship among these elements can be described as:

"Teachers develop the situation for students to explain, select a process for groupings of materials and students, build a bridge between what students already know and what they want them to learn, anticipate questions to ask and answer without giving away an explanation, encourage students to exhibit a record of their thinking by sharing it with others, and solicit students' reflections about their learning.”(George, 2001)

This brief overview indicates how these six elements integrate and work as a whole, but all need further explanation. In this paper, we would like to share our experience of the curriculum design for a year one unit SIT104 Introduction to Web Development and a year two unit SIT203 Web Programming offered in School of Information Technology at Deakin University, and understanding of these elements by reviewing students' learning activities observed in SIT104 and SIT203 classes during Trimester 2, 2012.

\section{Constructivist Learning Design}

\subsection{Situation}

According to (George, 2001), to design constructivist learning, teachers first have to design situation questions. For instance, what situation are you going to set up for students for demonstration purposes? Give students a scenario and describe a process of identifying problems, making assumptions, answering questions, trying solutions, drawing conclusions, or setting goals. This situation should include what you expect the students to do and how students will respond.

This element is well considered while we design the laboratory exercises for SIT203 Web Programming. The students enrolled in SIT203 come from different computer knowledge background. A few of them from business school have limited Programming experience. We first introduced the basic programming facilities necessary for completing the later laboratory tasks, then created different Web programming examples, setting up different development problems for consecutive weeks. Each week students were expected to solve particular problems step 
by step and the answers found in that week would be the key to answer next week's questions. The students were encouraged to post their solutions in tutorial contribution folder on CloudDeakin (an online learning system employed by Deakin University) to share thoughts.

All these laboratory solutions are also keys to solve assignment questions. Students practicing laboratory exercises would find assignment was much easier as they could modify the code used in laboratory exercises. Those students who did not attempt the exercises were encouraged to "re-do" their work when having difficulties with the assignments.

By setting up situations, students were led to solve problems step by step towards the final learning goals.

\subsection{Groupings}

There are basically two categories of groupings: one is students' groupings, another is materials' groupings.

For the first category, teachers need to decide how to make groupings of students and what process will be used to group them. For instance, groupings as individuals, or as teams of three, four, five or more. All these depend on the situation that teachers design and the materials available to them.

For the second category, teachers need to decide how to organise groupings of materials that students will use to explain the situation by visually demonstrating or verbally describing, about their experience. Usually the numbers of sets of materials groups determines the numbers of student groups to be formed.

We did not make any student groupings in SIT203 class but from the observation, students were forming their own study groups naturally. They sat together while attending lectures and laboratories, and discussed together while doing assignments.

This natural grouping helps students share knowledge and experience, improving group members' learning efficiency in some degree.

\subsection{Bridge}

Bridge is a very important activity used to determine students' prior knowledge and to build a "bridge" between what they already know and what they need to learn. This might involve such things as giving students a simple problem to solve, giving a similar example in real life, or having a class discussion, etc. It is recommended in (George, 2001) that bridge is best done before students are in groups and sometimes after they are grouped.

We find building a knowledge bridge is extremely important for the students to understand complex concepts. For instance, in SIT203, before introducing different encryption solutions in security system, first we had to make sure that students knew the basic encryption algorithms. A few simple questions were asked to evaludate their levels. If the answers were not satisfying, we would usually start from the basic concepts, and discuss deeper ones only after most of them understood the fundamental.

For their easy understanding, simulating complex concepts with reality examples is a good method. Quite a lot of students accepted new concepts easier with given physical models and real cases. "cut and choose" pie example was given to explain "cut and choose" principle in anonymous electronic cash; carbon paper was used to simulate blinded signature. These bridge examples did help students understand new ones by bridging between old and new knowledge.

\subsection{Questions}

Questions take place during each element of the constructivist learning design. They are used to test students' background knowledge. Similarly, teachers can use guiding questions to introduce the situation, arrange the groupings, set up the bridge, keep active learning going, prompt exhibits, and encourage reflections. When explaining complicated concepts, we kept asking students questions directing them to follow our talking. Based on the observation, we found most of the questions we asked were also the questions in their mind while trying to understand the concepts.

Asking questions is also a good approach to calling students attention. It works very well in all of the classes when we find students are somewhat absent of minded. Calkins (Calkins, 1986) argued that in most classrooms, we neither teach students to ask questions in schools nor allow students to ask questions, but simply require them to answer our questions, although asking questions is a challenging and important part of thinking and learning, especially if students are continually encouraged to ask more appropriate and more effective questions. Besides of asking questions, teachers also need to encourage students to ask questions therefore making them active learners. This would help them explain their thinking and support them in continuing to think for themselves. 
Every time when introducing new knowledge, we would ask students if they had any questions. Sometimes we got positive feedback but not always. It is almost an unwritten rule that students overwhelmingly email teachers asking questions about assignment when it is nearly due. In SIT203, a Frequently Asked Questions (FAQ) was edited based on students' email and released on CloudDeakin. This FAQ technique received lots of positive comments from students.

\subsection{Exhibit}

Exhibit involves having students make an exhibit for others of how they analyze a particular problem or case (George, 2001). This could include giving a verbal presentation, drawing a graph, chart, or other visual representation, acting out or role playing their impressions, creating a physical model, and referencing/making a digital video, photographs or poster for display.

Information delivered in a creative and attractive style definitely encourages students to start on their own self learning journeys.

In SIT203, we benefited from the exhibit approach. When introducing security techniques of protecting an e-commerce website, we thoroughly searched the library and YouTube website, found excellent videos explaining key features of a secured website, as shown in Figure 1 and 2. A question sheet was designed based on video contents requiring students to complete while watching the videos. The sheets were marked and released with answers afterwards.

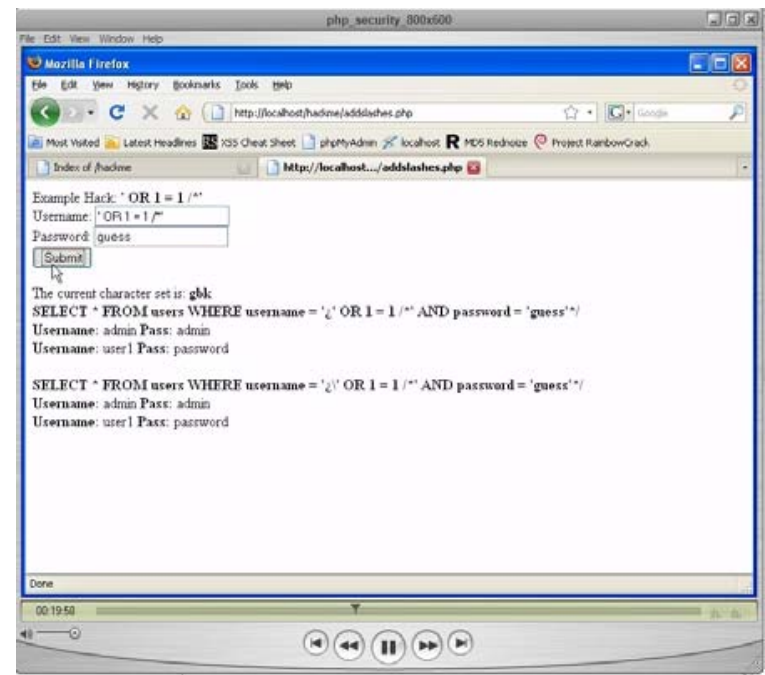

Figure 1: PHP Security Video on YouTube

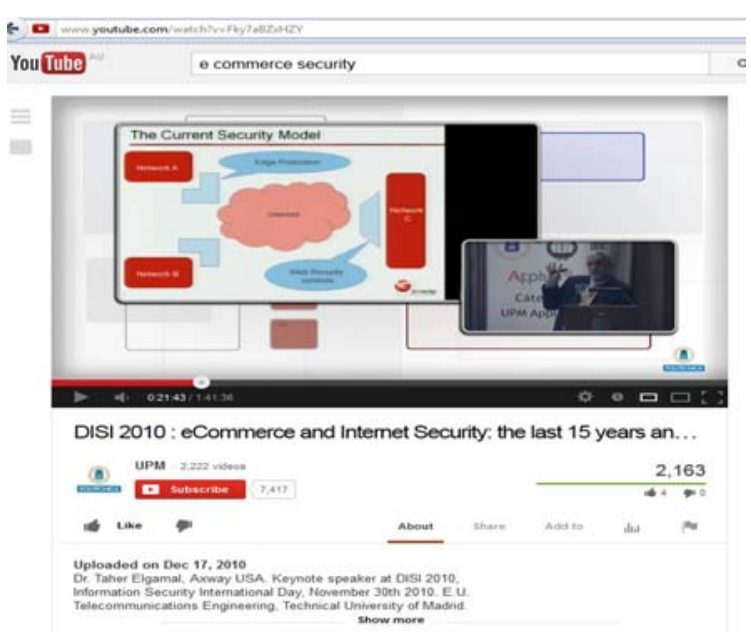

Figure 2: e-Commerce and Internet Security Video Screenshot 
From the conversation with students during class interval, an outstanding student was identified who is very active in computer security and even running a series of security conferences in Australia wide. He was invited to give the students an in-class presentation and he did an excellent job even attracting many students from other units.

By practicing constructivist learning theory, lectures are becoming so different and students are attracted in some degree and becoming more interested in the unit content.

\subsection{Reflections}

Reflections are the attitudes, skills, and concepts that students will take from the learning process.These reflections are what we need to consider while designing curriculum. Besides of reflecting our teaching, we encourage students to reflect what they learn in every class.

As a part of CloudDeakin, ePortfolios have been seen as a tool for lifelong learning and reflection. In SIT104, we designed an ePortfolio form requiring students to answer a few reflection questions for every assignment they attempted. These ePorfolio forms could be added to their ePortfolio profile which tracks the learning activities and develop a greater awareness of what students have learnt throughout years of University study, in order to better articulate their skills and gain entry to the professional sphere.

A sample ePortfolio profile is displayed in Figure 3, where various types of personal ePortofilio artifects are kept, such as form, presentation, folder, reflection, URL, etc.

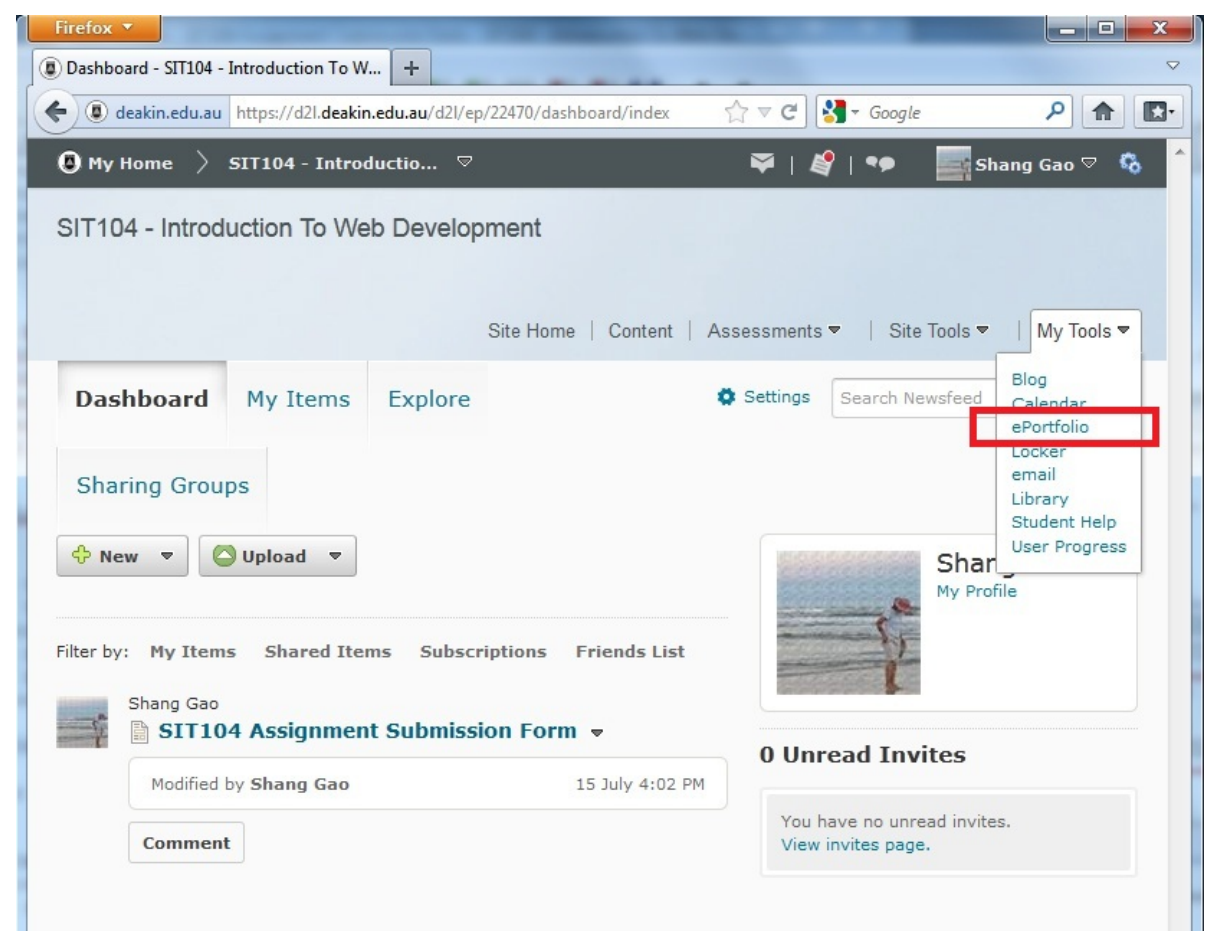

Figure 3: Sample ePortfolio Profile in CloudDeakin 


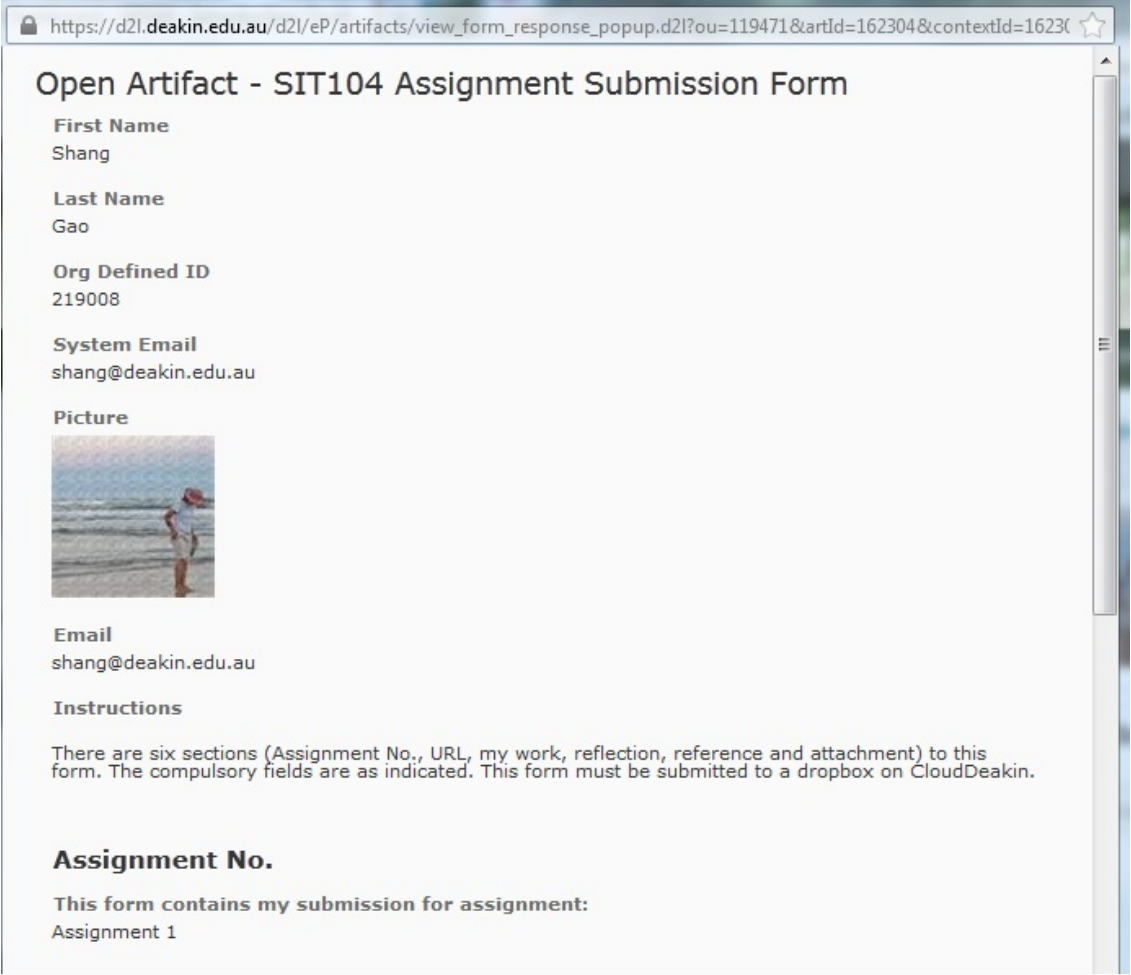

Figure 4: Sample ePortfolio Form in CloudDeakin

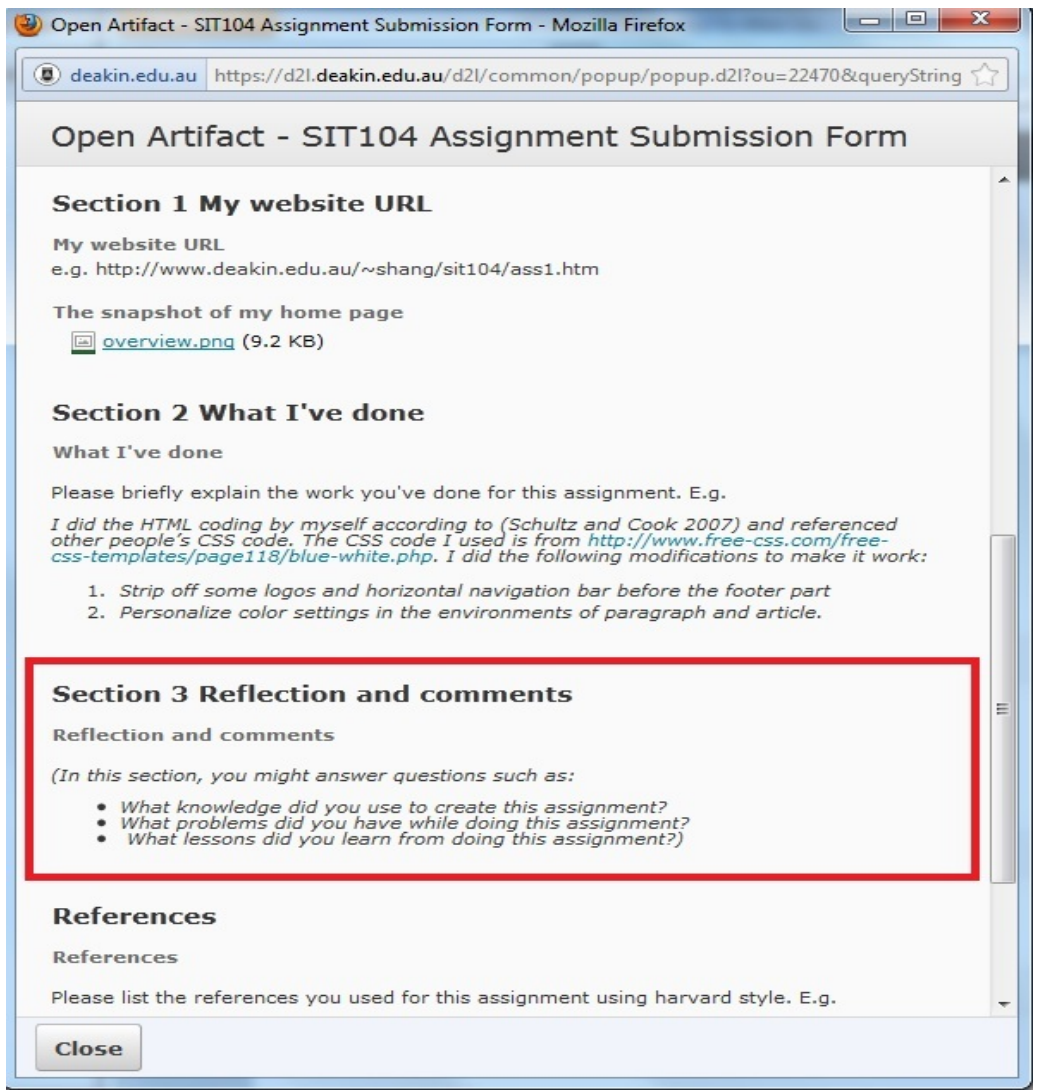

Figure 5: Reflection Questions Designed in ePorfolio Form 
Figure 4 and 5 list the ePortfolio form and its reflections questions required in SIT104 assignment submission form.

\section{Applications}

From the above discussion on the six elements, we can see that constructivist learning and teaching approach is based on actively engaging students in situations that involve collaboratively considering their own explanations for resolutions to problems, or formulation of questions. Through this approach,

- Students are encouraged to actively construct their own knowledge by learning from the designed situation by themselves with support and guidance from the teacher.

- Teachers design the learning situation and then provide encouragement and questions to students or groups who are trying to construct their own explanations.

We believe this approach can be applied to any subject area or curriculum by involving students as different learners and active participants instead of same listeners and passive recipients of information given to them by the teacher. After successful trials in SIT104 and SIT203 in trimester 2, 2012, we plan to apply this constructivist learning and teaching approach in other units at next stage. Further improvement and necessary adjustment is expected through teaching practice.

\section{Summary}

Constructivist teaching is an interesting and exciting way to teaching because students are involved in learning activities they appear to enjoy, and much more student-teacher contact is possible.

The possibilities for constructivist activities are limitless. It is important, however, regardless of subject area, to provide enough activities to engage them in the learning process. While applying the constructivist learning theory in practice, teachers need to keep in mind that students are different learners who have different learning ways and approaches. While designing practical, laboratory exercises, assignments and final exams, teachers are always recommended to take account of diverse preferences, goals and experiences.

Curriculum development is an evolving process that in itself is constructivist. In this process, teachers are also making their personal developmental and changing their own personal constructs about teaching at the same time.

\section{Acknowledgements}

The ePortfolio section is part of "Developing academic literacies in IT" project supported by Deakin University Participation and Partnerships Program (DUPPP).

\section{References}

Calkins, L. (1986). The art of teaching writing. Portsmith, NH: Heinemann.

Candy, P. C. (1991). Self-direction for Lifelong Learning: A Comprehensive Guide to Theory and Practice. San Francisco: Jossey-Bass.

George W. Gagnon, Jr., \& Michelle Collay. (2001). Constructivist Learning Design. Retrieved from http://www.prainbow.com/cld/cldp.html

Goodlad, J. (1984). A place called school. New York: McGraw-Hill

SIT104 CloudDeakin website (2013), Deakin University. Retrieved from www.deakin.edu.au/clouddeakin

Stacey, E. (1998). Overview of constructivist and social constructivist theories in relation to adult learners. Study of the enhancement of learnng through group interaction by computer mediated communication, unpublished doctoral thesis, Monash University, Melbourne.

www.ask.com website. (2001). Curriculum Development Models Tyler? Retrieved from http://www.ask.com/question/curriculum-development-models-tyler 